\title{
Application of UPFC on Stabilizing Torsional Oscillations and Improving Transient Stability
}

\author{
Yasser M. Alharbi \\ Ministry of Higher Education, \\ Saudi Arabia \\ King Abdullah scholarship \\ Program \\ y.alharbi77@gmail.com
}

\author{
A. Abu Siada \\ Electrical and Computer \\ Engineering Department \\ Curtin University \\ Perth, Australia \\ A.AbuSiada@curtin.edu.au
}

\author{
A. F. Abdou \\ School of SEIT \\ UNSW \\ ADFA \\ Canberra, Australia \\ a.abdou@adfa.edu.au
}

\begin{abstract}
This paper investigates the application of Unified Power Flow Controller (UPFC) to stabilize multi-mode torsional oscillations of sub-synchronous resonance (SSR), and to improve the transient stability during a three phase short circuit fault that may result in oscillatory torques on the generator rotor shaft causing serious damages to the system and may call for the disconnection of a wind farm to avoid any possible damages. Simulation is carried out using MATLAB/Simulink software. Results show that the proposed UPFC controller is very effective in damping all SSR modes of the system under study and in minimizing the potential for the wind farm disconnection during the studied faults. The proposed controller is simple and easy to be implemented.
\end{abstract}

Index Terms-Sub-synchronous Resonance (SSR), UPFC, Stability, Wind Farms.

\section{INTRODUCTION}

$\mathrm{P}$ OWER systems are becoming larger and more interconnected. As a consequence, transient stability problem has become more serious. If the stability is lost, network collapse may occur with annihilating economical losses and severe power grid damages that may lead to overall blackout [1-4]. Stability problem can occur due to the increase in the power demand with overloading the transmission lines, therefore, transmission line operators are required to increase the power transfer capability of the existing transmission lines. In this context, they have two options; the first one is to build an additional parallel transmission line which is not a cost effective option especially for long transmission lines. The second option is to use a series capacitor as a partial compensation reactance to the transmission line which has been extensively used as a very effective method to increase power transfer capability of transmission system, and improve the steady state and transient stability limits of a power system [5]. Series capacitor is however, not without a problem as it may cause subsynchronous resonance (SSR) when the mechanical frequency of the generator mechanical shaft and the electrical frequency of the transmission system are add up to the power frequency[6]. There are three ways in which a

Yasser M. Alharbi is with king Abdullah scholarship program (e-mail: y.alharbi77@gmail.com).

A. Abu-Siada is with the Department of Electrical and Computer Engineering, Curtin University, Perth, WA 6845 Australia (e-mail: a.abusiada@curtin.edu.au).

A. F. Abdou is with School of SEIT, UNSW@ADFA, Canberra, Australia e-mail: a.abdou@adfa.edu.au system and generator can interact with subsynchronous effects: induction generator effect, torsional interaction and transient torques[6]. SSR due to transient torque can be developed if an electrical resonant frequency of the network is complementary to any one of the natural torsional oscillating frequencies of turbine-generator shaft during system disturbance events. The electric resonance of the transmission system and the torsional oscillations of the mass-spring system of the turbine generator will be mutually excited and might grow up causing serious shaft oscillations resulting in shaft fatigue and possibly damage and failure [7]. The first two shaft failures due to SSR occurred at the Mohave power station in 1970 and 1971 respectively [8-10]. It is important to investigate the subsynchronous resonance when planning to include series capacitors for new or existing transmission lines. Extensive research has been introduced in the literature to increase the damping of torsional mode and many countermeasures have been suggested to damp the SSR. Some suggested solutions include the use of synchronous-machinebased Energy Storage System (ESS) [11], static var compensator (SVC) [12, 13], superconducting magnetic energy storage (SMES) unit [14-17], Static Synchronous Compensator (STATCOM) [18], shunt reactor controller [19, 20], Thyristor-controlled dynamic resistance braking [9, 21], excitation control of synchronous generator [22, 23], and gate controlled series capacitors [24, 25].

Flexible AC Transmission Systems (FACTS) based power electronic converters are used extensively in power systems because of their ability to provide flexible active and reactive power flow control [26]. This paper investigates the use of Unified Power Flow Controller (UPFC) to enhance transient stability and to damp the SSR of a steam turbine-generator that is connected to a large interconnected AC grid via a series capacitor compensated transmission line.

\section{SYSTEM UndER STUdY}

The system under study shown in Fig.1 consists of a synchronous generator and wind farm that includes 6 wind turbines of type D connected to the grid that is simulated as infinite bus via a $\mathrm{Y} / \Delta$ step down transformer and two parallel transmission lines, one of which is series compensated. The UPFC is connected to bus- 1 between the compensated transmission lines and the generators to provide adequate damping for the turbine generator set. 


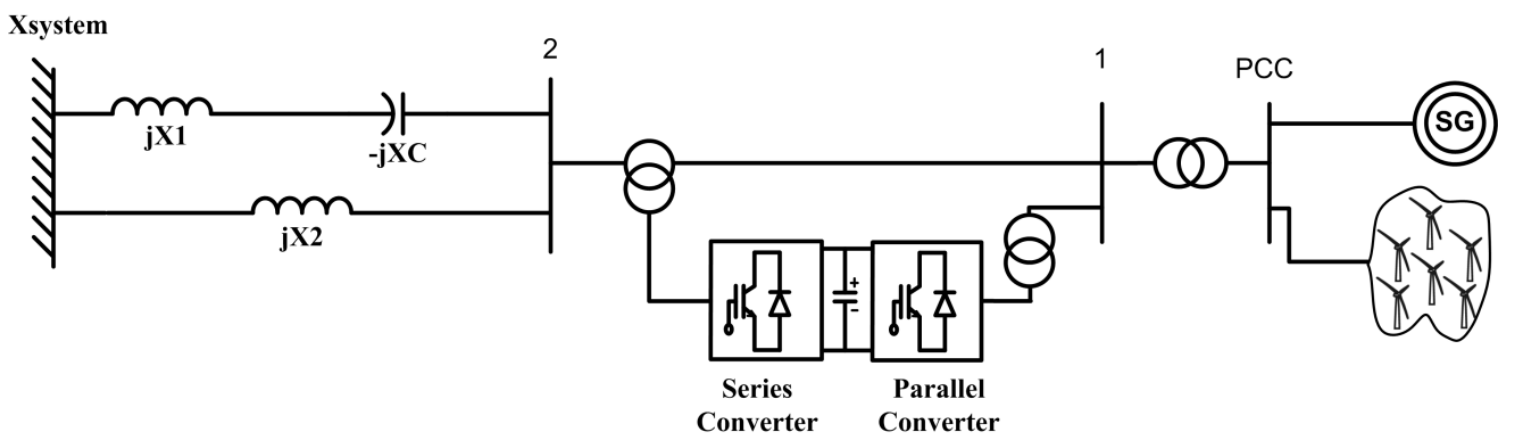

Fig. 1 System under study

\section{UPFC MODELING AND CONTROL}

A UPFC is a complex power electronic device developed to control and to optimize the power flow in electrical power transmission systems. UPFC is a combination of a STATCOM and Static synchronous series Compensator (SSSC) coupled through a common DC link. The UPFC allows system to be more flexible by using high-speed response active and reactive power compensations. Therefore, installing UPFC at critical points of the transmission system will increase the power dispatch up to the power rating of generators and transformers and the thermal limits of transmission line conductors, by increasing the stability margin. The shunt and series converters of the UPFC can control both active and reactive powers smoothly, rapidly and independently [26].

The series inverter is used to control the real and reactive line power flow by inserting a voltage of a controllable magnitude and phase in series with the transmission line. As shown in Fig.2. The active and reactive power error is used to generate the reference value of the $V_{\text {dref }}$ and $V_{\text {qref }}$ which is compared with the measured values of $V_{d}$ and $V_{q}$. The error signal is fed to PID controller to calculate the required converter firing angle and modulation index. The Clarke-Park transformation is used to convert the $a-b-c$ quantities to $d-q$ reference frame [27].

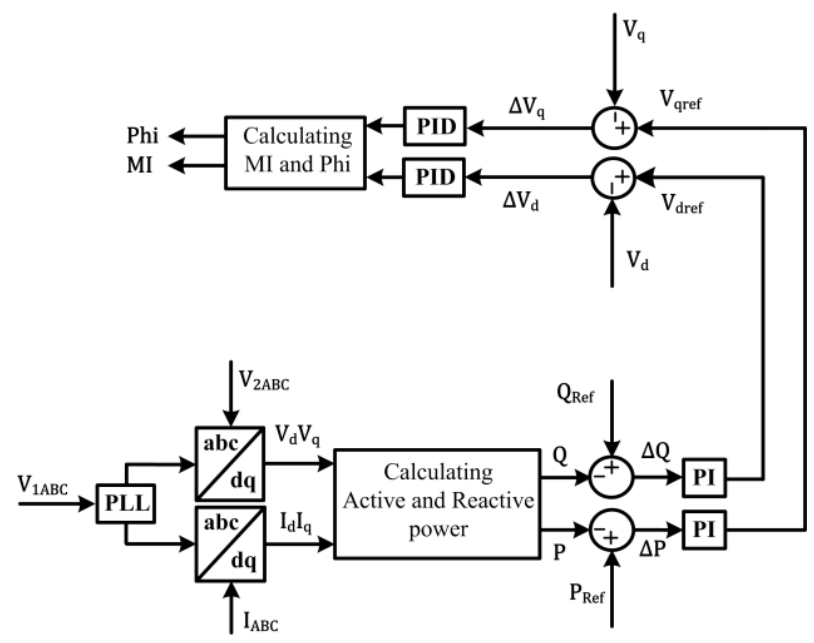

Fig. 2 Control system of the series converter
The shunt inverter is used for voltage regulation at the PCC by injecting reactive power into the transmission line and balancing the real power flow exchanged between the series inverter and the transmission line. The reference AC voltage and the DC converter voltage are compared with their measured bus values and the error is fed into a PI controller to create $i_{\text {qref }}$ and $i_{\text {dref }}$ which are compared with measured values $i_{q}$ and $i_{d}$. The error signal is fed to a PID controller to create the firing angle and modulation index for the shunt converter.

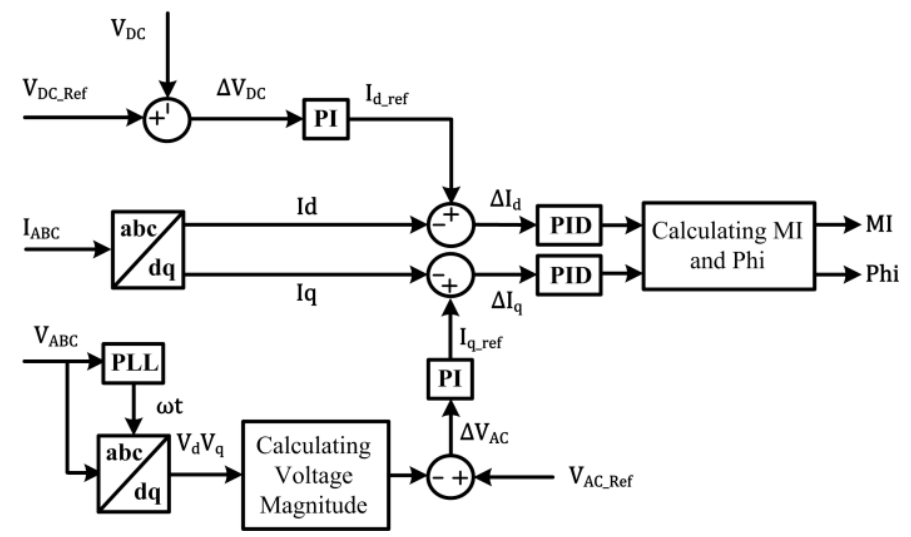

Fig. 3 Control system of the shunt converter

The robustness of the selected parameters is based on several runs that are conducted to the system, as shown in Fig.4. An $O F\left(K_{I}, K_{P}\right)$ is determined for the entire aggregate of runs, in which each run in the aggregate corresponds to one operating condition of the network.

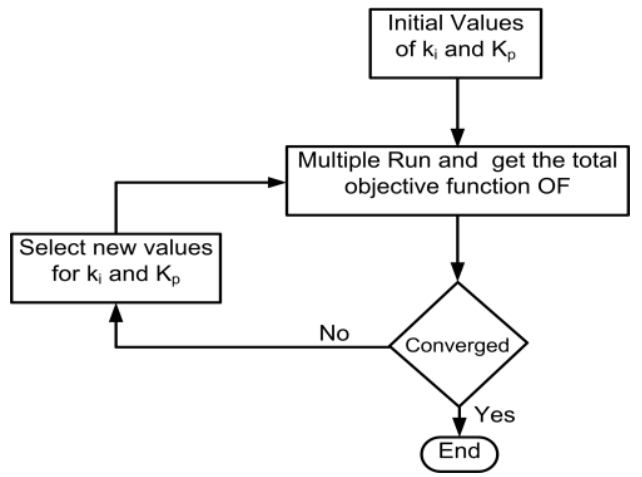

Fig. 4. Schematic diagram for selecting PI parameters 


\section{DAMPING OF SSR}

The shaft system of the turbine generator set consists of four masses; a high-pressure turbine (HP), a low-pressure turbine (LP), a generator rotor (Gen) and an exciter (Ex). To carry out the investigations, a non-linear model of the system is developed to incorporate the interaction between the electric network and the torsionally oscillating shaft system of the turbine-generator set. The system is simulated with the inclusion of all non-linearities such as exciter ceiling voltage limit and the limit of the PI parameters. A three phase shortcircuit fault is simulated at bus- 2 at $\mathrm{t}=12 \mathrm{~s}$ and is assumed to be cleared at $\mathrm{t}=12.035 \mathrm{~s}$.

Figs. 5 through 13 show the dynamic response of the studied system without and with the UPFC. The effect of the SSR and the UPFC controller is investigated through time domain waveforms of various system variables such as the synchronous generator speed deviation, torsional torque induced on the shaft sections between the high- pressure, lowpressure turbines $\left(\mathrm{T}_{\mathrm{HP}-\mathrm{LP}}\right)$ and the low-pressure turbine and generator $\left(\mathrm{T}_{\mathrm{Gen-LP}}\right)$, the DFIG electromechanical torque, the point of common coupling (PCC) voltage the DFIG converter DC voltage and the DFIG speed. Without UPFC and due to the lack of system damping, the system is unstable as evident by the high torsional forces induced in the generator mechanical shafts and the significant increment in the shaft speeds.

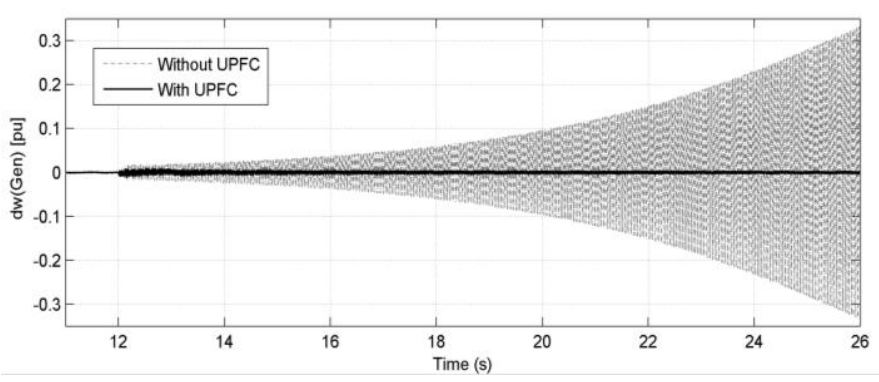

Fig. 5. Generator speed deviation with and without UPFC

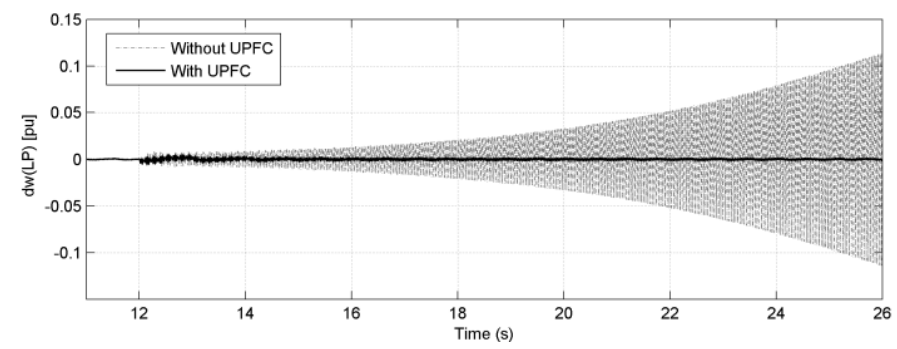

Fig. 6. LP speed deviation with and without UPFC

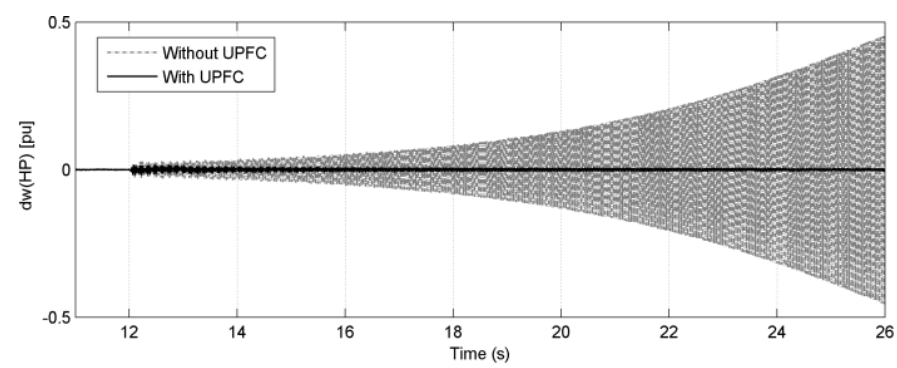

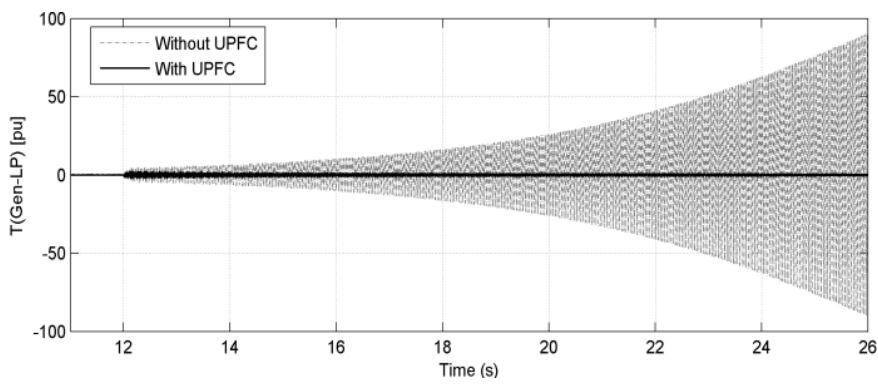

Fig. 8. LP to Gen Torque with and without UPFC

When the UPFC is connected, the damping of the synchronous generator and the DFIG are greatly enhanced and the stability margin can be extended as shown in the Figures. It can also be shown that using a UPFC unit will reduce high torsional forces on the turbine-generator shaft sections to almost normal steady state values and decrease the settling time substantially. It will also reduce the generator shaft speed oscillations and maintain the speed at the nominal value. The effect of improving system damping and the overall performance using UPFC is very obvious as can be seen in the simulation results.

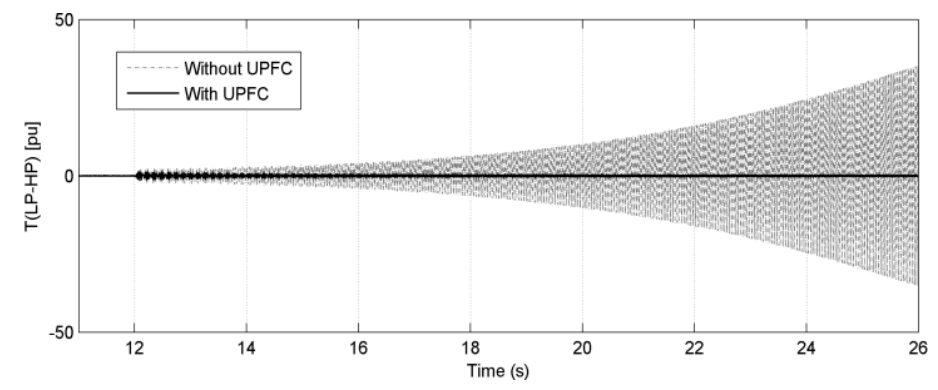

Fig. 9. HP to LP Torque with and without UPFC

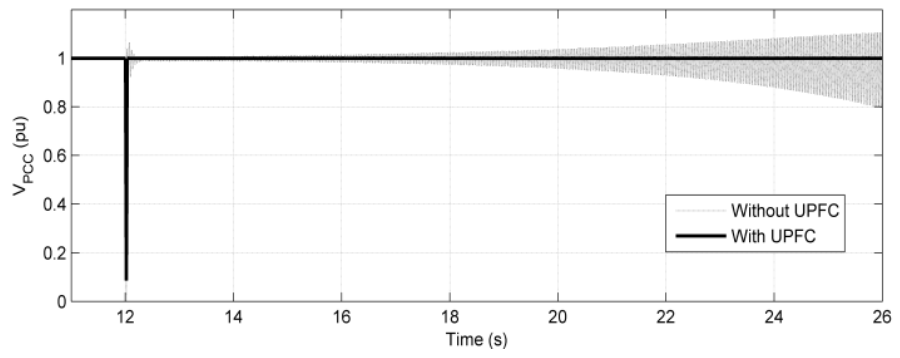

Fig. 10. The PCC voltage with and without UPFC

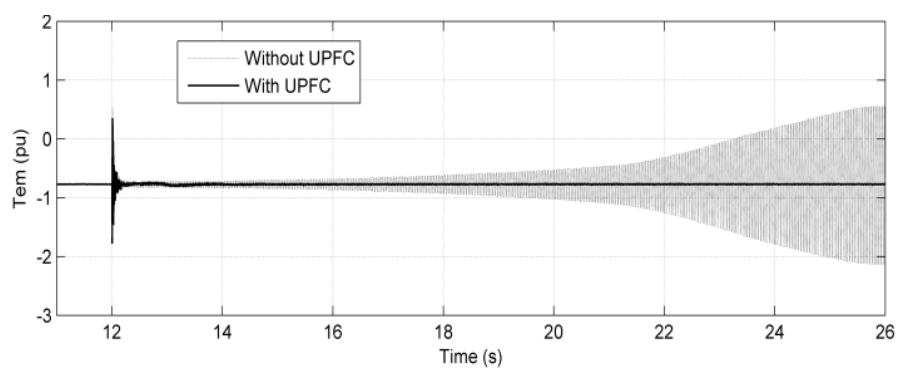

Fig.11. DFIG Electromechanical Torque with and without UPFC

Fig. 7. HP speed deviation with and without UPFC 


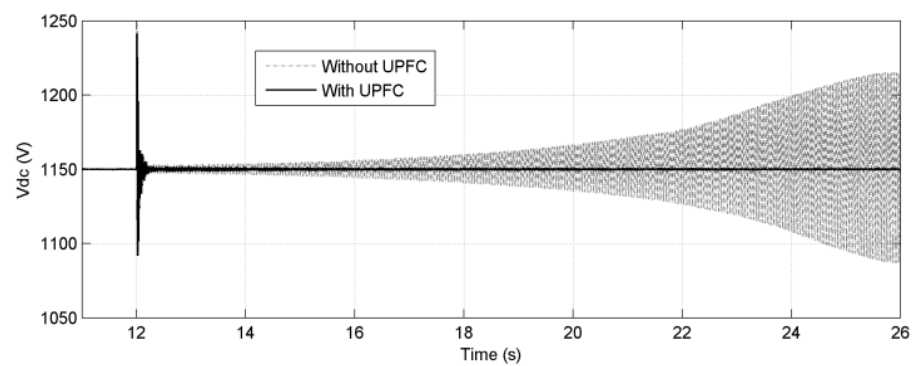

Fig.12. DFIG VDC response with and without UPFC

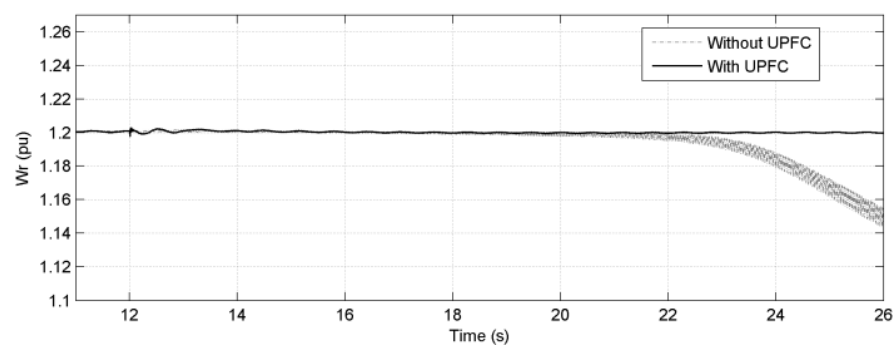

Fig.13. DFIG Speed with and without UPFC

\section{CONCLUSIONS}

Results show that the additional degree of freedom provided by the UPFC under the proposed controller significantly improves the system overall performance. The proposed control algorithm can effectively render active and reactive power support to damp system torsional oscillations and to enhance system transient stability during a three phase short circuit fault. This controller is simple in its structure and would require very little hardware to implement.

\section{REFERENCES}

[1] G. Andersson, et al., "Causes of the 2003 major grid blackouts in North America and Europe, and recommended means to improve system dynamic performance," Power Systems, IEEE Transactions on, vol. 20, pp. 1922-1928, 2005.

[2] M. D. Ilic, et al., "Preventing Future Blackouts by Means of Enhanced Electric Power Systems Control: From Complexity to Order," Proceedings of the IEEE, vol. 93, pp. 1920-1941, 2005.

[3] A. F. Abdou, A. Abu-Siada, and H. R. Pota, "Application of STATCOM to improve the LVRT of DFIG during RSC firethrough fault," in Universities Power Engineering Conference (AUPEC), 2012 22nd Australasian, 2012, pp. 1-6.

[4] N. K. Roy, H. R. Pota1, M. A. Mahmud, and M. J. Hossain, "Voltage control of emerging distribution systems with induction motor loads using robust LQG approach," International Transactions on Electrical Energy Systems, 2013.

[5] J. Machowski, J. W. Bialek, and J. R. Bumby, "Power System Dynamics and Stability," ed: John Wiley \& Sons.

[6] K. R. Padiyar, Power System Dynamics New Delhi : BS Publiations 2008

[7] A. F. Abdou, A. Abu-Siada, and H. R. Pota, "Damping of subsynchronous oscillations and improve transient stability for wind farms," in Innovative Smart Grid Technologies Asia (ISGT), 2011 IEEE PES, 2011, pp. 1-6.

[8] R. G. Farmer, A. L. Schwalb, and E. Katz, "Navajo project report on subsynchronous resonance analysis and solutions," Power Apparatus and Systems, IEEE Transactions on, vol. 96, pp. 12261232, 1977.

[9] W. Li and L. Ching-Huei, "Application of dynamic resistance braking on stabilizing torsional oscillations," in TENCON '93. Proceedings. Computer, Communication, Control and Power Engineering.1993 IEEE Region 10 Conference on, 1993, pp. 145148 vol.5.
"First benchmark model for computer simulation of subsynchronous resonance," Power Apparatus and Systems, IEEE Transactions on, vol. 96, pp. 1565-1572, 1977.

L. Ha Thu and S. Santoso, "Increasing wind farm transient stability by dynamic reactive compensation: Synchronous-machine-based ESS versus SVC," in Power and Energy Society General Meeting, 2010 IEEE, 2010, pp. 1-8.

H. Zhou, et al., "Improvement of Transient Voltage Stability of the Wind Farm Using SVC and TCSC," in Power and Energy Engineering Conference (APPEEC), 2011 Asia-Pacific, 2011, pp. $1-4$.

A. F. Abdou, A. Abu-Siada, and H. R. Pota, "Application of SVC on stabilizing torsional oscillations and improving transient stability," in Power and Energy Society General Meeting, 2012 IEEE, 2012, pp. 1-5.

A. Abu-Siada, "Damping of large turbo-generator subsyncronous resonance using superconducting magnetic energy storage unit," in Universities Power Engineering Conference (AUPEC), 2010 20th Australasian, 2010, pp. 1-4.

J. B. X. Devotta, M. G. Rabbani, and S. Elangovan, "Application of superconducting magnetic energy storage unit for damping of subsynchronous oscillations in power systems," Energy Conversion and Management, vol. 40, pp. 23-37, 1999.

W. Li, L. Shin-Muh, and H. Ching-Lien, "Damping subsynchronous resonance using superconducting magnetic energy storage unit," Energy Conversion, IEEE Transactions on, vol. 9 , pp. 770-777, 1994.

O. Wasynczuk, "Damping Subsynchronous Resonance Using Energy Storage," Power Engineering Review, IEEE, vol. PER-2, pp. 36-37, 1982.

A. F. Abdou, A. Abu-Siada, and H. R. Pota, "Application of a STATCOM for damping subsynchronous oscillations and transient stability improvement," in Universities Power Engineering Conference (AUPEC), 201121 st Australasian, 2011, pp. 1-5.

E. Eitelberg, J. C. Balda, E. S. Boje, and R. G. Harley, "Stabilizing SSR oscillations with a shunt reactor controller for uncertain levels of series compensation," Power Systems, IEEE Transactions on, vol. 3, pp. 936-943, 1988.

L. Wang and C.-H. Lee, "Stabilizing torsional oscillations using a shunt reactor controller," Energy Conversion, IEEE Transactions on, vol. 6, pp. 373-380, 1991.

R. M. Hamouda, Z. R. Alzaid, and M. A. Mostafa, "Damping torsional oscillations in large turbo-generators using Thyristor Controlled Braking Resistors," in Power Engineering Conference, 2008. AUPEC '08. Australasian Universities, 2008, pp. 1-6.

A. Ghorbani and S. Pourmohammad, "A novel excitation controller to damp subsynchronous oscillations," International Journal of Electrical Power \& Energy Systems, vol. 33, pp. 411419, 2011.

W. Li, "Damping of torsional oscillations using excitation control of synchronous generator: the IEEE Second Benchmark Model investigation," Energy Conversion, IEEE Transactions on, vol. 6, pp. 47-54, 1991.

F. D. Jesus, E. H. Watanabe, L. F. W. Souza, and J. E. R. Alves, "Analysis of SSR Mitigation Using Gate Controlled Series Capacitors," in Power Electronics Specialists Conference, 2005. PESC '05. IEEE 36th, 2005, pp. 1402-1407.

R. Rajaraman, et al., "Computing the damping of subsynchronous oscillations due to a thyristor controlled series capacitor," Power Delivery, IEEE Transactions on, vol. 11, pp. 1120-1127, 1996.

Y. M. Alharbi, A. M. Shiddiq-Yunus, and A. Abu-Siada, "Application of UPFC to improve the LVRT capability of wind turbine generator," in Universities Power Engineering Conference (AUPEC), 2012 22nd Australasian, 2012, pp. 1-4.

A. F. Abdou, A. Abu-Siada, and H. R. Pota, "Effect of Intermittent Voltage Source Converter Faults on the Overall Performance of Wind Energy Conversion System," International Journal of Sustainable Energy, pp. 1-13, 2013. 